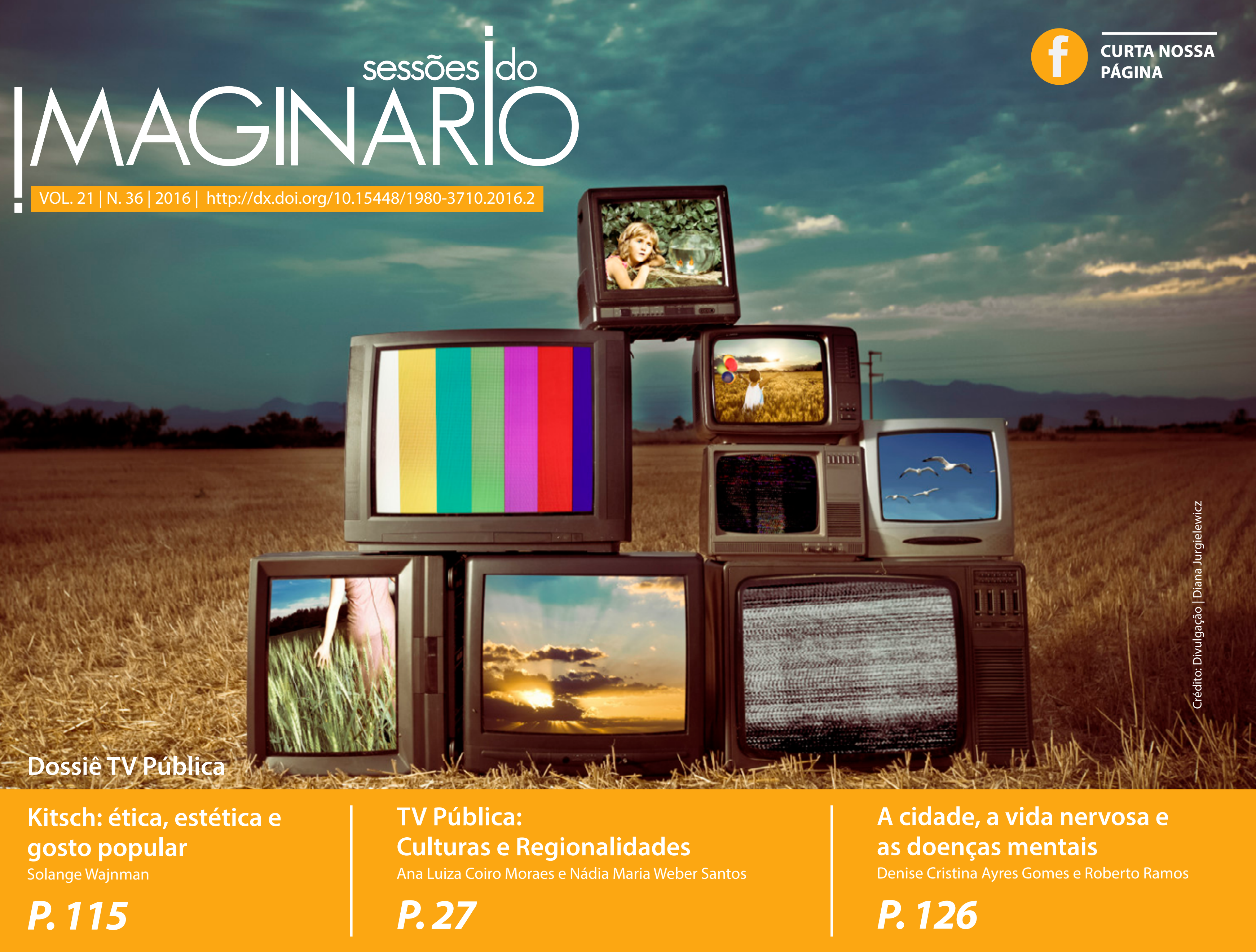




\section{A potência pedagógica da cultura visual}

The pedagogical power of visual culture

Sabrina da Silva Gava'

\section{RESENHA}

Resenha da obra: MIGLIORIN, Cezar. Cartas sem reposta: a internet, a educação, o cinema e o Luciano Huck. Belo Horizonte: Autêntica, 2015.

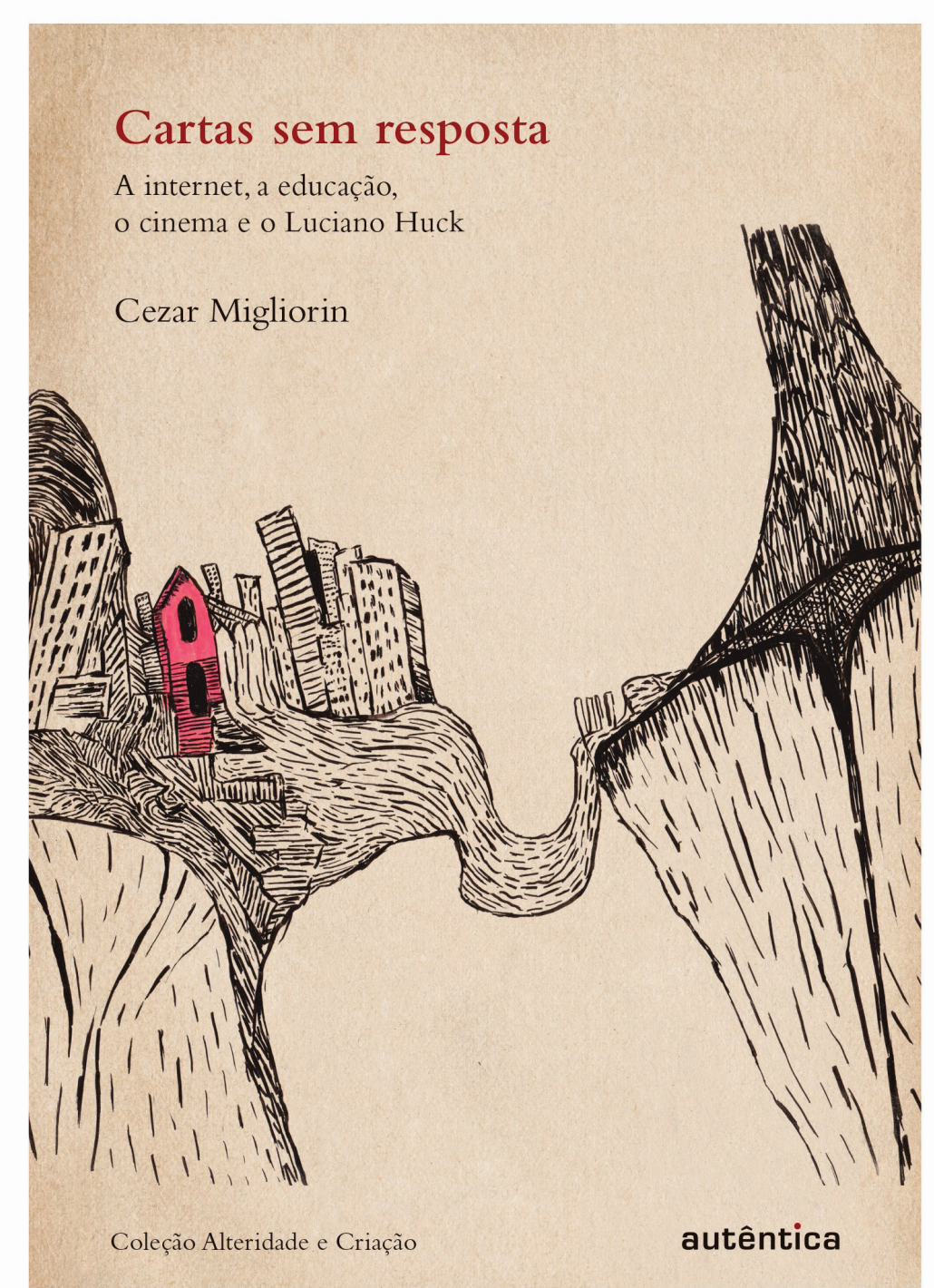




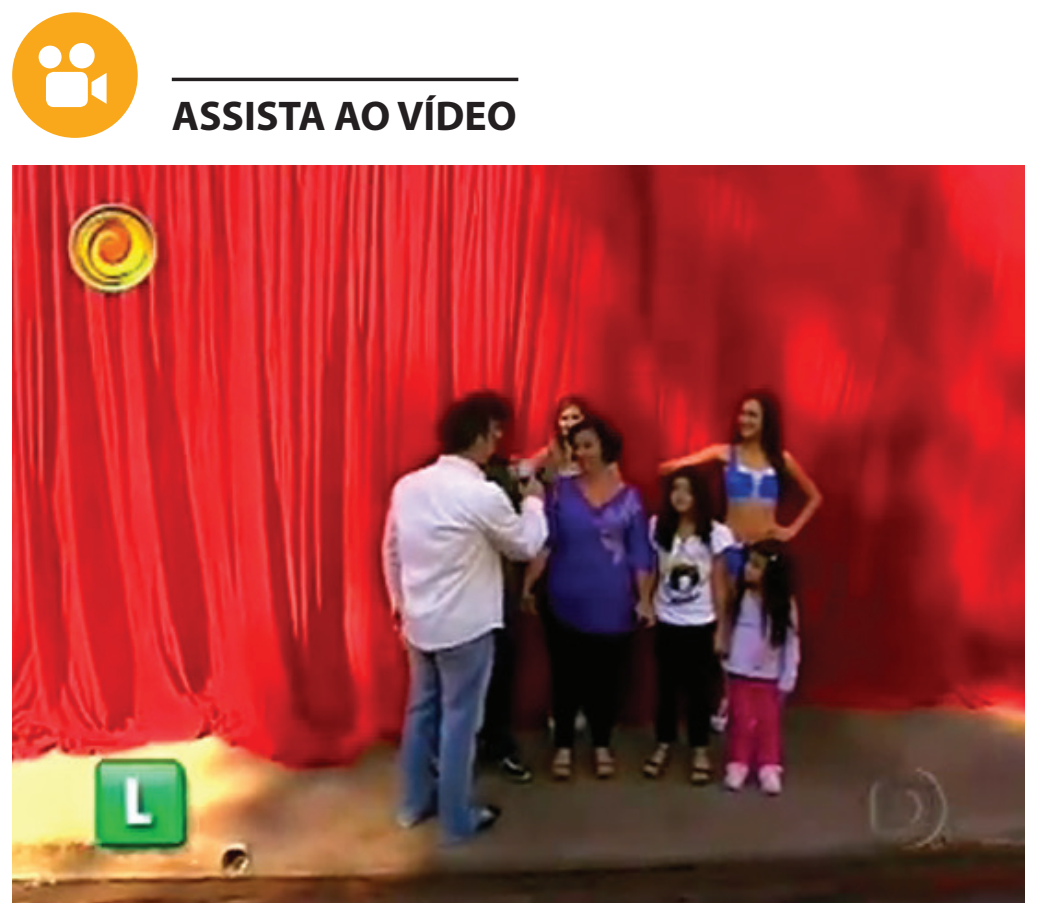

Trecho do quadro Lar Doce Lar

Escrita em forma de cartas, a obra de Cezar Migliorin $^{2}$ busca dialogar com diferentes personalidades identificáveis no meio cultural sobre a televisão, o cinema e a internet - universos midiáticos nos quais a sociedade é construída e que lidam com as formas das pessoas serem vistas e se verem, com as formas de ser e de se pensar hoje.

Lançado em 2015, durante a 10a Mostra de Cinema de Ouro Preto (CINEOP), o livro é na verdade uma tentativa de fazer com que o leitor perceba os pressupostos políticos e subjetivos que estão latentes nos programas de TV, filmes, matérias de jornal e até em conversas de bar, e reflita sobre a possibilidade de se pensar novos conhecimentos, a partir de uma aproximação entre Educação, Cinema e Mídias Contemporâneas. Questões que, muito bem articuladas e embasadas, vão se expandindo e se correlacionado nas seis cartas que integram a obra verdadeiros ensaios críticos que envolvem a filosofia e a teoria da imagem.

A primeira carta destina-se ao apresentador Luciano Huck. Nela, Migliorin faz uma crítica respeitosa ao programa Lar Doce Lar, uns dos quadros pertencentes ao programa Caldeirão do Huck, que é produzido e exibido pela Rede Globo. Como se fosse um amigo, o autor critica a forma como a equipe do programa adentra a casa dos participantes, destruindo e modelando a mesma. Para o autor, é violenta a presença da Globo na casa dos participantes, uma vez que a equipe do programa desfaz o trabalho de uma vida inteira, eliminando marcas subjetivas e pessoais. Assim, "No lugar do lar se cria um espaço espetacularizado à imagem da emissora" (Migliorin, 2015, p. 23). Nesse espaço, novos gostos estéticos são adquiridos e novas formas de consumo são induzidas. A comunidade desaparece, na medida em que as outras casas do bairro não são filmadas e os vizinhos são isolados por grades, a maioria impossibilitada de participar da cena. O pior tudo é que o apresentador parece ter consciência disso, mas prefere justificar a ação da emissora com cinismo: "destruímos a história, destruímos o trabalho dos outros, destruímos a poesia porque somos a Globo e a gente faz" (Migliorin, 2015, p. 22). Nesse ponto, as reflexões que Migliorin propõe ao apresentador e ao leitor são as seguintes: a Globo faz, mas a que custo? A custo dos participantes perderem a própria identidade? A custo de serem colocados como o outro de classe, o desfavorecido cuja história é espetacularizada para fazer render audiência? Segundo a lógica do programa, é essa história sofrida que faz com que os participantes mereçam a casa nova - mas isso significaria dizer que as outras pessoas da comunidade não têm histórias suficientemente boas para também merecerem uma casa nova? Migliorin termina a carta convidando o apresentador a conhecer o seu laboratório de pesquisa, a fim de estreitar laços entre a universidade (ambiente de discussões acerca do audiovisual e do outro) e o programa (que trabalha com o documentário, consequentemente, com pessoas reais, que vibram e sofrem de verdade).

A segunda carta destina-se ao cineasta Newton Cannito. Nela, Migliorin faz uma crítica ao documentário Jesus no Mundo Maravilha (Newton Cannito, 2007), um filme que se sustenta nas histórias de três ex-policiais militares que trabalham num parque de diversões; de um casal que chora a perda do filho, negro, morto pela polícia e a de um palhaço que passa o tempo todo negociando sua participação no documentário. Num primeiro momento, o autor elogia o filme, dizendo que ele "é monstruoso, com as seduções que podem ter os monstros" (Migliorin, 2015, p. 29). A meu ver, um elogio que diz respeito, sobretudo, à ironia com que o roteirista trata a violência e o combate à criminalidade, o velho

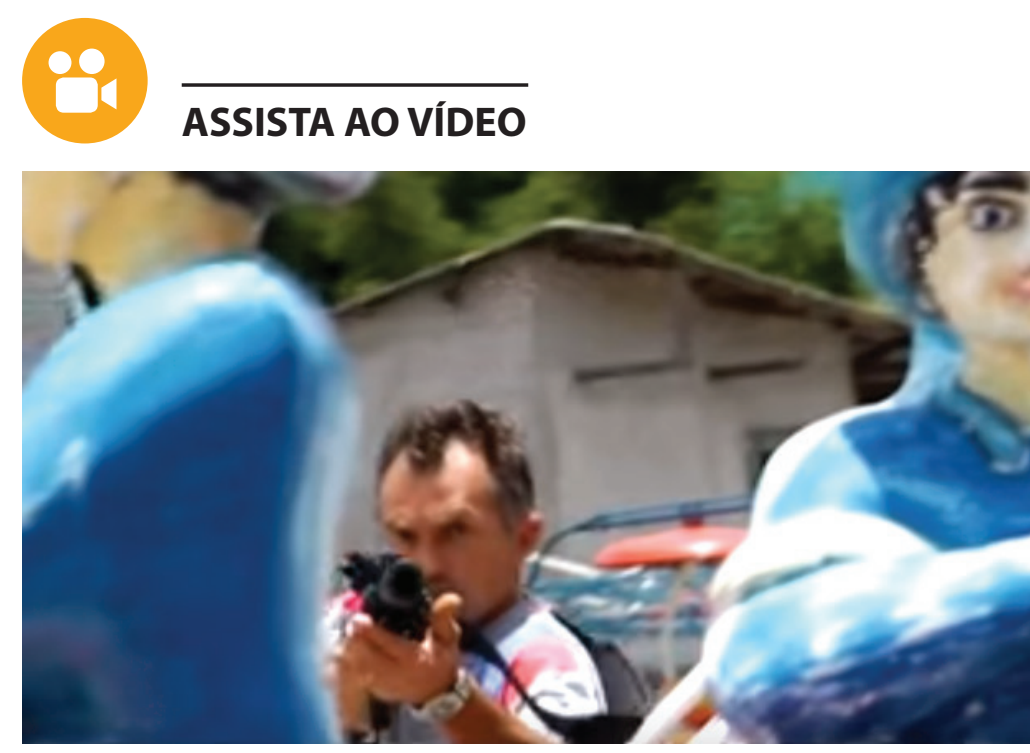

Trecho do documentário Jesus no Mundo Maravilha 
jogo entre polícia e ladrão. Nesse jogo, quem é o policial, quem é o bandido e quem é o palhaço da história? Cada um tem a sua versão, a sua posição que tende a eliminar a do outro e é aí que surge a primeira crítica de Migliorin: o roteirista parece não acreditar nas palavras de seus próprios personagens. "Por isso elas podem ser confrontadas com o carrossel, com a trilha do circo, com os jogos de guerra, com os efeitos cômicos" (Migliorin, 2015, p. 29). O autor critica mais alguns pontos a esse respeito, mas nada comparável à crítica que faz sobre a participação do palhaço no documentário. Submetido ao poder da imagem e da mídia, o palhaço é obrigado a escutar do roteirista: "Por que eu estou te entrevistando?'", "'Eu não te chamei para estar aqui [...]'" (Migliorin, 2015, p. 38-39). Segundo Migliorin, a violência e o desprezo que o roteirista parece alimentar por aquele homem banal o faz desejar que o mesmo seja destruído com a imagem em que tanto deseja estar - um fim bastante comum para aqueles que veneram os meios de comunicação de massa.

A terceira carta destina-se ao escritor Bernardo Carvalho. Nela, Migliorin faz uma crítica ao artigo intitulado Em defesa da obra, que foi publicado na revista Piauí. Partindo "do princípio de que os autores existem, que eles fazem obras, vivem vidas e que essas obras e vidas são hoje disputadas pelas grandes corporações da internet que desejam tudo publicizar e obter lucro [...]" (Migliorin, 2015, p. 43), o artigo discute questões que envolvem a autoria das obras de arte e a sociabilidade em rede. Trata-se, pois, de uma crítica às corporações da mídia que buscam expandir a quantidade de obras criativas disponíveis, através de licenças com menos restrições que o tradicional copyright, de modo a facilitar o seu compartilhamento e recombinação, sobretudo, na

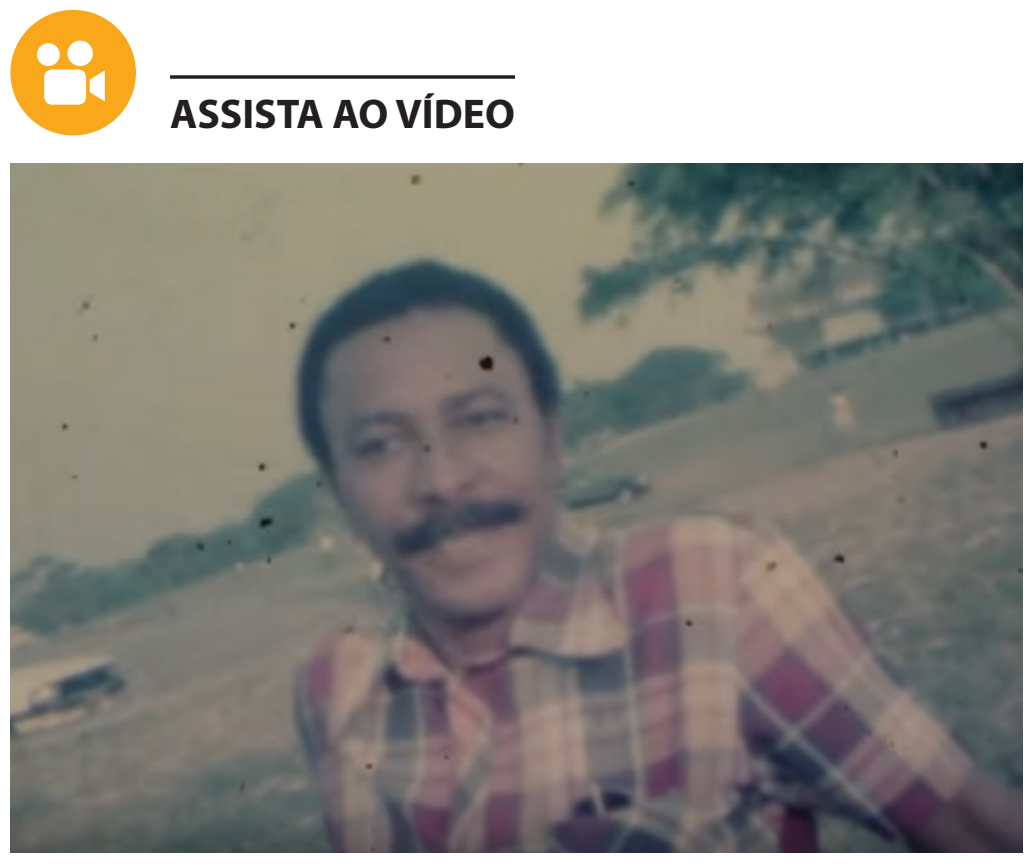

Trecho do documentário Os Dias com Ele

internet. Migliorin parece criticar o modo como o escritor enxerga esta, isto é, como um meio de transmissão daquilo que existe, desconsiderando que ela pode possibilitar mundos e engendrar processos subjetivos e políticos. Migliorin também critica o escritor no que se refere à oposição escola/internet: "Se colocas que a escola é transmissão, regra e trabalho, enquanto que a internet é prazer, futilidade e repetição, perdemos o melhor dos dois mundos, uma vez que a educação e a cultura não estão nem em um nem em outro, mas em redes [...]" (Migliorin, 2015, p. 48) das quais resultam novas formas de relações intelectuais, afetivas, sociais e políticas.

A quarta carta destina-se à cineasta Maria Clara Escobar. Nela, Migliorin faz uma análise do documentário Os dias com ele (Maria Clara Escobar, 2013), no qual a cineasta mergulha no passado quase desconhecido de seu pai, Carlos Henrique Escobar, um militante na época da ditadura militar. Como salienta o autor, trata-se de "[...] um filme perturbador sobre a resistência de um personagem a uma filha que o deseja, como personagem histórico, como personagem fílmico e como pai" (Migliorin, 2015, p. 58). Nesse documentário, Migliorin dá destaque à tensão existente entre pai e filha, pois, durante a entrevista, ambos estão tentando inventar um lugar para si. Mas a crítica do autor não se dirige a essa tensão. A crítica, nesta carta, dirige-se especificamente ao pai. Para ele, as pessoas e o mundo não mereciam um filme sobre eles. Indignado, Migliorin faz duas interpretações possíveis dessa fala: ou o mundo é feito de pessoas inferiores aos dois, ou o mundo é maior que os dois e não merece o encontro deles. Ao fim, o autor discorda das duas, preferindo acreditar que o mundo merece sim este filme, pois as histórias de pai e filha, personagem e diretora, não mais os pertencem; antes, fazem parte do cinema e do mundo.

A quinta carta destina-se ao escritor Marcus Faustini. Retomando uma conversa que tivera com ele, Migliorin discute a questão da diferença e diz que só é possível discutir o assunto tomando a arte e os sujeitos que estão na vida. A arte permite uma intensificação da própria diferenciação, por conseguinte, dos possíveis sujeitos e comunidades. Os sujeitos fazem parte de um todo em transformação e se relacionam com forças, poderes e criações que os transformam e que são transformados por eles. Por isso, não podemos dizer que existem sujeitos diferentes uns dos outros, mas sujeitos que diferem em si mesmos. "O sujeito configura-se como atualizações de um agenciamento, de um emaranhado heterogêneo de afetos, estéticas, poderes, etc." (Migliorin, 2015, p. 67). Daí que não podemos conhecer e transformar o sujeito 
a partir de uma realidade. Por exemplo, diz o autor: para viver plenamente os seus processos subjetivos, um negro discriminado precisa afirmar "ser negro" para ter o direito de não sê-lo. Ou seja, ao afirmar ser negro, o sujeito de cor negra deixa de ser um produto do meio, que lhe dá uma identidade, e passa a entrar em um processo de subjetivação que é individual e coletivo, simultaneamente. Assim, ele deixa de ser "[...] a representação de um ideal definido pela história, pelo movimento, pela polícia, pela nova linha de cosméticos [...]" e passa a ser "[...] um ser negro que é em si uma transformação, diferença de si e do que esperamos que seja." (Migliorin, 2015, p.70). Partindo dessa análise e colocando-se diante da política da diferença, Migliorin questiona: "como facilitar os possíveis se não sabemos quais sujeitos e comunidades se atualizaram?" (Migliorin, 2015, p. 71).

A última carta destina-se aos professores. Nela, Migliorin fala da relação entre a universidade e o mercado de trabalho no capitalismo contemporâneo. Segundo o autor, nessa fase não interessa mais que o trabalhador saiba fazer, mas que ele saiba ser. A produção de subjetividade passa a ser o capital humano da empresa e a mercadoria-serviço nada vale se não for sustentada por capacidades relacionais. Isso acontece porque o mercado atual não trata mais os trabalhadores como na fase fordista, isto é, desprovidos de seus gostos, hobbies, família e lazer. Ao contrário, ele incorpora esses saberes e gestos e vai buscar nas universidades os "modos de vida" que o interessa. Na visão do autor, o mercado e a universidade estão em constante diálogo e é fictícia a ideia de separação entre estudar e trabalhar. Mas, apesar de existir esse diálogo, a universidade não pode ser pautada pelo mercado. "A pergunta 'preparar ou não para o mercado' corre o risco de colocar à sombra a im- portância da universidade como espaço de invenção de novas formas de intervenção na sociedade e nos territórios." (Migliorin, 2015, p. 79). Como diz Migliorin, formamos para a vida e não para uma capacitação imediatista.

Enfim, à espera de respostas, as cartas continuam friccionando nosso pensamento em torno da Educação, do Cinema e das Mídias Contemporâneas. Fruto de conversas, textos e filmes que o provocaram, o livro não foi pensado apenas para a leitura de especialistas e pesquisadores interessados no assunto. Sua linguagem é de fácil compreensão e nos instiga a conhecer todas as obras e autores com os quais está dialogando. Assim encerro estes escritos fazendo um convite ao leitor para que conheça essa obra provocadora, instigante e atual de Cezar Migliorin.

Notas

1 Mestranda do Programa de Pós-graduação em Educação (Processos Socioeducativos e Práticas Escolares em Educação) da Universidade Federal de São João del-Rei (UFSJ) (Praça Dom Helvécio, 74, Bairro Dom Bosco, CEP 36301-160, São João del-Rei/MG). E-mail: sabrinasgava@hotmail.com.

2 Doutor em Comunicação e Cinema (Eco UFRJ/ Sorbonne Nouvelle, Paris). Chefe do Departamento de Cinema e Vídeo da Universidade Federal Fluminense (UFF), membro do Programa de Pós-Graduação em Comunicação da mesma universidade, cooordenador do Laboratório Kumã de pesquisa e experimentação da imagem e do som e co-coordenador do Seminário Temático da Socine: Cinema, estética e política: a resistência e os atos de criação. Ensaísta, pesquisa e publica sobre o cinema brasileiro, sobretudo o campo do documentário em seus aspectos estéticos e políticos, e desenvolve projetos que envolvem Cinema e Educação. É autor do livro A menina e organizador do livro Ensaios no real: o documentário brasileiro hoje, ambos editados pela Editora Azougue. 